\title{
La excedencia voluntaria en el Derecho local
}

\author{
por \\ ANTONIO MARTINEZ BLANCO
}

Secretario del Ayuntamiento de Aguilas.

SUMARIO: I. Introduccion.-II. Las situaciones administrativas: 1. Idea general. 2. Las posibles causas de estas situaciones. 3. Plan del presente trabajo.-III. Antecedentes históricos: La excedencia como licencia ilimitada: 1. Idea general. 2. Los Reglamentos de Secretarios de Ayuntamientos de 1902, 1905 y 1916. 3. El Reglamento de funcionarios municipales de 1924. 4. El Reglamento de funcionarios administrativos de 1928. 5. La Ley municipal de 1935. 6. El Reglamento de funcionarios de Administración local de 1952. 7. Antecedentes en la legislación de los funcionarios del Estado: a) Ley y Reglamento de funcionarios de 1918. b) La Ley de 1954 sobre situaciones administrativas. c) Las Leyes del Movimiento de Reforma administrativa.-TV. Fuentes: 1. Directas. 2. Supletorias. 3. Complementarias. 4. Por vía de analogía.-V. Concepto y naturaleza: 1. Concepto doctrinal. 2. Concepto legal.-VI. Fundamento.VII. Conclusiones.

\section{INTRODUCCION}

La teoría de la excedencia voluntaria no es ciertamente de las básicas y fundamentales del Derecho administrativo, como raíz y principio de otras instituciones, sino que más bien confluyen y desembocan en ella las consecuencias de otras teorias tales como las de «continuidad del servicio público», «relación jurídica del funcionario con la Administración», etc., y tienen además su reflejo en la misma casi la serie completa de derechos de los funcionarios, económicos, al ascenso, pasivos y demás.

Si por esta razón no es abundante la doctrina sobre la excedencia, sin embargo, por su frecuente utilización práctica, plan- 
tea una serie de problemas, sobre todo en orden al reingreso del funcionario que se encuentra en esta situación, que han sido abordados con reiteración por la Jurisprudencia.

La actualidad de la materia se evidencia, además, en virtud de las siguientes consideraciones:

a) La desaparición de los servicios de gestión de determinadas exacciones, motivada por la supresión de éstas, que llevó a cabo la reciente reforma de la Hacienda local, con amortización o declaración de «a extinguir» de numerosas plazas de plantilla de las Corporaciones locales, trajo consigo efectos de especial gravedad para los funcionarios en situación de excedencia voluntaria.

La rigidez legal por un lado, y un sentido de equidad, que es también fuente del Derecho, por otro, han sido los dos polos opuestos de presión que han forzado al especialista del Derecho local a buscar soluciones nuevas a un problema que, si no es de ahora, ha aflorado recientemente con especial vigor por el motivo expuesto.

b) Las revistas profesionales han venido, por otra parte, llamando la atención de los funcionarios sobre las desagradables e irreparables consecuencias que en orden al reingreso del excedente voluntario puede reportarles tal situación, aun en circunstancias normales, aunque éstas sean a veces paliadas por la condescendencia de la propia Administración.

c) Añadamos a esto que una institución pensada como peculiar de un Derecho de acusado respeto a la libertad individual, como el español, en favor exclusivo del funcionario, cual la excedencia voluntaria, puede resultar perjudicial o no conveniente en determinadas circunstancias para la buena marcha del mismo servicio, que por paradoja constituye la justificación última de numerosas limitaciones de la esfera individual de libertad, sacrificada con justicia en aras del superior interés público que aquél representa.

Es por esto que últimamente se han alzado voces en el sentido de limitar esta institución a más estrechos límites, pues su «fundamento y razón de ser, tal como hoy está concebida, hay 
que considerarlos contrarios a los principios básicos que deben presidir la regulación de la función pública» (1).

d) Por último, las recientes disposiciones que de manera más o menos directa afectan a esta situación (supresión de su límite temporal máximo en el Derecho local, ordenación nueva de las consecuencias que el matrimonio comporta para la mujer funcionario), unido a la imperfecta configuración de la excedencia activa (que se ve reconducida a la excedencia voluntaria) y a la aparición también reciente de una Ley articulada para los funcionarios de la Administración del Estado, con el simultáneo anuncio por otra parte de otra Ley del Derecho local, la de emolumentos de los funcionarios de este orden, de una futura integración «hasta donde sea deseable» de la función pública en España, son motivos todos que evidencian la actualidad de la materia e incitan a un estudio de la institución, como una aportación más a esa anunciada reforma del Derecho local, que pudiera ser la ocasión para solucionar aquellos problemas y perfeccionar otros aspectos de esta institución en los términos a que nos conducirán las consideraciones que siguen.

\section{LAS SITUACIONES ADMINISTRATIVAS}

\section{IDEA GENERAL.}

El funcionario está ligado con la Administración en virtud de una relación jurídico-pública cuya naturaleza ha sido y es objeto cie controversia doctrinal, en cuya virtud viene obligado primariamente a la prestación de sus servicios a aquélla (2).

(1) DE LA VALLINA VelaRde, Juan Luis: «Las situaciones administrativas de los funcionarios públicos», Revista de Administración Pública, núm. 39, 1962, pág. 484.

(2) Recientemente ha dicho Royo VILLANova, resumiendo el estado actual de la cuestión, que la mayor parte de los autores niegan el carácter contractual de la relación de la función pública. Pero aún cabe discutir la virtualidad del acto de nombramiento y de la aceptación del funcionario. ¿Es esta aceptación condición de eficacia o un elemento esencial integrador del acto ? ( $\ll \mathrm{El}$ concepto de funcionario público y la relación de función pública en el nuevo Derecho español», en $R$. $A$. $P$., núm. 44, 1964, págs. 19-20).

Para Plantey, la concepción de cada sistema nacional respecto de la fun- 
La situación fundamental del funcionario, según esto, es la de servicio activo. Pero pueden excepcionalmente surgir causas de la más diversa índole que afecten a la permanencia en tal servició por parte del funcionario, e incluso a la propia relación jurídica de servicio, dando lugar a una variada gama de situaciones jurídicas que pueden ir desde la licencia por corto espacio de tiempo hasta la baja definitiva.

Es clara la consecuencia de que en definitiva tales situaciones. encuentran su principal razón de ser en el interés del propio funcionario de encontrarse en circunstancias de no prestación de servicio conservando todos o la mayor parte de sus derechos. Al propio tiempo, la Administración, al par que satisface evidentes exigencias de justicia, según los casos, pone los medios jurídicos para conservar al funcionario que, tras las pruebas reglamentarias, tiene acreditada su eficacia y experiencia en el transcurso del tiempo al servicio de aquélla.

No es del caso el estudio de cada una de aquellas causas, de las razones que justifican sus peculiares efectos jurídicos en este orden o de la regulación jurídica vigente en el Derecho local o central en cada caso. Especialmente nos hemos propuesto en este trabajo el estudio de aquel grupo de causas que comúnmente se vienen agrupando bajo el título de excedencia voluntaria.

El funcionario de Administración local que por definición legal desempeña servicios de carácter permanente (3) puede encontrar-

ción pública determina el predominio reśpectivo de las teorias contractual y estatutaria. (Traité pratique de la fonction publique. París, 1956.)

En nuestro concreto ordenamiento, según GarRIDo FALLA, se ha establecido un régimen de función pública en que el nombramiento de los funcionarios se realiza a través de un acto administrativo unilateral, aunque señala que nada se opone en principio a que el Derecho positivo hubiere optado por el procedimiento contractual. (Tratado de Derecho administrativo, volumen ㅍ, Madrid, 1960, págs. 58-9.)

Puede verse, sobre este problema, Serra PINAR: «Naturaleza de la relacion jurídica que une al funcionario con la Administración», en Estudiols dedicados al profesor Gascón y Marin. Madrid, 1952.

(3) «Son funcionarios de Administración local los que en virtud de nombramiento legal desempeñan en las entidades $u$ organismos que la constituyen servicios de caracter permanente, figuren en las correspondientes plantillas y perciban sueldos o asignaciones fijas con cargo a los presupuestos respectivos» (artículo 319 de la Ley de Régimen local, texto refundido de 24 de junio de 1955). 
se, aparte de la situación que hemos considerado normal de «servicio activo», en otras situaciones excepcionales que vienen reguladas con gran perfección por su Reglamento.

Tales son: a) Expectación de destino. b) Interrupción del servicio activo. c) Cese en el servicio activo, y $d$ ) Baja definitiva del funcionario, que por otra parte no es propiamente situación jurídica funcionarial (4).

$Y$ es que, con relación a la prestación de sus servicios, el funcionario puede o no haber comenzado a prestarlos, o dejar de prestarlos; en este segundo caso, bien de modo transitorio-con reserva o no de plaza-, o bien de modo definitivo. De este modo, tendríamos las siguientes posibilidades o situaciones jurídicas generales: a) No haber tomado posesión de la plaza a que tiene derecho (expectación de destino); b) Dejar de prestar servicio por causas justificadas que recoge su status jurídico, y que por su corta duración o escasa trascendencia no le desvinculan del cargo o plaza que desempeña en propiedad (interrupciones del servicio) ; c) Dejar de prestar servicio por causas asimismo justificadas que regula la Ley, pero que por su carácter voluntario unido a su larga duración, o por llevar consigo la supresión de la plaza, privan al funcionario de ésta, aunque continúe vigente la relación jurídica de servicios (cese en el servicio activo), y, por último, d) Dejar de prestar servicio definitivamente por haberse extinguido la propia relación de servicios que le ligaba a la Administración (baja definitiva).

\section{LAS POSIBLes CAUSAS DE ESTAS SITUACiONES.}

La colocación de las diversas figuras jurídicas, que definan específicamente las múltiples situaciones posibles, dentro del anterior esquema, es por lo demás algo accidental y variable en función del criterio del legislador o del jurista, pues, en general, esta materia, aun respondiendo en sus líneas básicas a principios objetivos y universales, no puede llevarse a sus últimas consecuen-

(4) Arts. 40 a 73 del Reglamento de 30 de mayo de 1952, de funcionarios de Administración local. 
cias de detalle con un sentido de uniformidad objetiva y absoluta.

Por lo que hace a los funcionarios de Administración local, y dentro de aquella situación genérica de «cese en el servicio activo», nos encontramos junto a la destitución y la pena de suspensión por tiempo superior a seis meses, otro conjunto, típico ya en el Derecho administrativo español de funcionarios, de situaciones denominadas con acierto por el Reglamento de 1952 «las excedencias».

A su vez, la excedencia puede ser, siguiendo a este cuerpo legal: $a$ ) forzosa ; $b$ ) activa; $c$ ) por matrimonio, y $d$ ) voluntaria (5). Suprimido el apartado c) del artículo 56 de dicho Reglamento por cl Decreto de 1 de marzo de 1962, en aplicación de la Ley de 22 de julio de 1964, a los funcionarios femeninos de Administración local, las posibles modalidades de aquélla han quedado reducidas a las tres de forzosa, activa y voluntaria.

\section{Plan del presente trabajo.}

De la excedencia llamada voluntaria nos ocuparemos especialmente a lo largo de este estudio, haciendo a la excedencia en general o a aquellas otras modalidades las referencias necesarias para la debida comprensión de la primera. Todo ello en relación fundamentalmente con los funcionarios de Administración local (6), sin olvidarnos de su conexión con la legislación de los funcionarios civiles del Estado.

\section{(5) Art. 56, ibidem.}

Como excedencia especial, con los derechos que se señalan en el artículo 13, párrafo primero, de la Ley de 15 de julio de 1954, fué considerada la de los funcionarios de Administración local, que con autorización del Ministerio de la Gobernación, oída la Corporación local, sean contratados por algún organismo internacional, por los Servicios de Asistencla Técnica de las

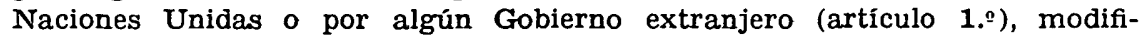
cándose la Ley de Régimen local de 17 de julio de 1945, texto refundido de 24 de junio de 1955, en Ios términos establecidos por la Ley de 17 de julio de 1958, reguladora de tal situación.

(6) Como casos especiales de funcionarios al servicio de la Administración local pueden citarse los sanitarios y el personal de la Agrupación Temporal Militar colocado en Corporaciones de este orden.

El personal de los Servicios sanitarios locales, que se rige por el Reglamento de 27 de noviembre de 1953 y disposiciones complementarias o 
$Y$ dentro de aquélla nos ocuparemos singularmente de su concepto, antecedentes históricos, naturaleza y fundamento, supuestos y efectos, con especial detenimiento en los fundamentales problemas del carácter de su concesión, del derecho al reingreso al servicio activo y conexiones con las otras clases de excedencia muy próximas a la voluntaria.

\section{ANTECEDENTES HISTORICOS: LA EXCEDENCIA COMO LICENCLA ILIMITADA}

\section{IDEA GENERAL.}

Desde las primeras regulaciones referentes a los Secretarios de Ayuntamientos, y más tarde de funcionarios municipales, hasta llegar al Reglamento de 1952, se recoge la excedencia voluntaria configurándola como un caso de licencia ilimitada (a partir de 1924 con la limitación inicial de un año de plazo mínimo de

posteriores, disfruta de una situación de excedencia voluntaria calcada de la regulación que llevó a cabo un año antes el Reglamento de funcionarios de Administración local de 30 de julio de 1.952, con las ligeras variantes a que haremos referencia a lo largo del presente trabajo. Aunque hay que advertir que hoy, cobrando sus sueldos con cargo a los Presupuestos del Estado, como exige la Ley de funcionarios civiles del Estado, artículo 2..$^{\circ}$ párrafo 2, letra $c$ ), les será de aplicación tal Ley, con modificación del mencionado Reglamento y disposiciones complementarias.

Las situaciones dentro de la Agrupación Temporal Militar para Servicios civiles, son los de: a) Colocado; b) En expectacion de destino; c) De reemplazo voluntario. (Artículo 17 , Ley 15 de julio de 1952, modificado por Ley 30 de marzo de 1954.)

El personal de esta Agrupación «colocado» en plazas de la Administración local, está con relación a ésta en situación de activo, de la que pueden pasar a la excedencia forzosa (y paralelamente a la de «expectación de destino» en la Agrupación), activa (y paralelamente a la de «reemplazo voluntario» en la Agrupación) o voluntaria. Pero para esta última sólo en el caso de enfermedad; si el funcionario colocado desea cesar en el destino, debe solicitar la de «reemplazo voluntario» deniro de la Agrupación, con arreglo a los preceptos señalados en la Orden de la Presidencia del Gobierno de 21 de febrero de 1955. (Artículo 2. de la Orden de 19 de julio de 1956, sobre licencias a personal de la Agrupación.)

En cuanto al disfrute de licencias temporales, prórrogas reglamentarias $y$ permisos, se equipara totalmente al resto del personal donde preste sus servicios. (Artículo 1. Orden mencionada.)

En resumen: el personal de la A. T. M. colocado en Corporaciones locales sólo puede disfrutar de excedencia voluntaria por causa de enfermedad. 
duración), procediéndose a la declaración de vacante y nombramiento por concurso, por entenderse que el interesado renuncia ai cargo.

Será el Reglamento de funcionarios de Administración local de 1952 el que con una ordenación mucho más perfecta, detallada y sistemática, y con relación ahora a todo el funcionariado local, regulará propiamente la excedencia voluntaria en los términos que aquí la estudiamos, como un caso de «cese» en el servicio activo, y con perfecia delimitación de las licencias propiamente dichas, que lo son de mera «interrupción» del mismo.

\section{Los Reglamentos de Secretarios de Ayuntainientos} DE 1902, 1905 y 1916.

En el Reglamento provisional de Secretarios de Ayuntamientos y de los servicios encomendados a estos funcionarios, aprobado por Real Decreto de 23 de agosto de 1916, que recogió a su vez el Reglamento, también de Secretarios de Ayuntamientos, aprobado por otro Real Decreto de 14 de junio de 1905, en lo fundamental coincidente con el aprobado por Real Orden de 8 de agosto de 1902 (que no llegó a regir por haber suspendido indefinidamente su aplicación la Real Orden de 23 de diciembre de 1902), regula la «licencia ilimitada o excedencia» como uno de los casos en que el Secretario de Ayuntamiento puede hacer uso de licencia, en cuyo caso se procederá a la declaración de la vacante y al nombramiento por concurso, entendiéndose que renuncia a la plaza que desempeña, quedando en libertad para poder optar a los concursos que le convengan (artículo 38,4 ).

\section{El REgLAMENTO DE FUNCIONARIOS MUNICIPALES DE 1924 (7).}

En idénticos términos la reguló el Reglamento de Secretarios de Ayuntamiento; Interventores de Fondos y Empleados municipales en general, aprobado por Real Decreto de 22 de agosto de 1924, con relación a los Secretarios, con la limitación ahora de no

(7) El Reglamento de funcionarios y subalternos provinciales, aprobadc por Real Decreto de 2 de noviembre de 1925, sigue una técnica semejante, remitiéndose en cuanto a las licencias (excedencias) de los Secretarios 
poder optar éstos a los concursos que les convengan hasta después de transcurrido un año en esta situación (artículo 32,3 ).

Otra novedad es la extensión de la institución a gran parte del funcionariado local (la total extensión no se logrará efectivamente hasta el Reglamento de 1952). Con relación a los Interventores de Fondos y Jefes de las Secciones provinciales de Presupuestos se establece la misma facultad en la forma y condiciones establecidas para los Secretarios (artículo 76). $Y$ con relación a los «empleados municipales» en general, los Reglamentos de cada Corporación determinarían el régimen de licencias aplicables a sus empleados de todas clases, pero como mínimo ha de reconocérseles el derecho a la licencia ilimitada, con carácter de excedencia voluntaria, en el caso y con los requisitos que se previenen para los Secretarios (artículo 114).

\section{El RegLAMENTO DE FUNCIONARIOS ADMINISTRATIVOS DE 1928.}

Ante el escaso cumplimiento que dieron los Ayuntamientos a la obligación que les impusieran el Estatuto (8) y el Reglamento citado de 1924 (9) de redactar Reglamentos «para el régimen de sus funcionarios técnicos, administrativos y subalternos», se dictó el Reglamento orgánico provisional por el que habían de regirse aquéllos, siendo aprobado por Real Orden de 14 de mayo de 1928.

Pero a pesar de su carácter supletorio con relación a los de las Corporaciones, que se dictaron en escaso número, y que el de 1924 se había remitido a éstos en materia de excedencia volun-

ai Reglamento de Servicios internos de cada Corporación, siempre que «la excedencia» lleve consigo la declaración de vacante (art. 36). Para los Interventores se remite al Reglamento de Interventores y Empleados municipales de 23 de agosto de 1924, al Estatuto provincial (que no contiene ningún precepto sobre licencias o excedencias) y Reglamento de la Corporación, salvo lo dispuesto en contra por el propio Reglamento (art. 43). Para el personal administrativo y subalterno se remite en cuanto a «licencias y excedencias» al Reglamento de servicio interior, pero con sujeción a lo prevenido en el articulo 114 del Reglamento de Empleados municipales de 23 ce agosto de 1924 (art. 55).

(8) Fué aprobado por Real Decreto de 8 de marzo de 1924. Esta obligación a que se alude estaba recogida en su artículo 248.

(9) Artículo 93. 
taria, no se ocupó al regular las licencias de la excedencia volintaria, sino a la originada por servicio militar y forzosa por supresión de plazas por reforma de plantilla (artículo 27). Por ello, para las licencias de los Secretarios e Interventores se remite al Reglamento de 1924 (artículo 4.9), y para los empleados administrativos (cerrando perfectamente un magnífico círculo vicioso) a los Reglamentos que establecerán las Corporaciones, aunque se añada ahora una «guía». para llevarlos a cabo, el de funcionarios del Estado de 7 de septiembre de 1918 (10), si bien en consonancia con el de empleados municipales de 1924 y el definitivo de provisión de destinos públicos de 6 de febrero de 1928 (artículo 14).

\section{LA LEY MUNiCIPAL DE 1935 (11).}

No se ocupó esta Ley de 1935, siguiendo el precedente de los Estatutos, de las licencias o excedencias, antes bien y en su disposición transitoria décima deja en vigor provisional, entre otros, los Reglamentos de 23 de agosto de 1924 sobre funcionarios municipales y el de 14 de mayo de 1928 sobre funcionarios administrativos.

Sin embargo, regula dos facultades a favor de los funcionarios municipales en expectativa de destino, que son por lo tanto aplicables al excedente voluntario, en orden a su reingreso, y que no hemos visto recogidas por el Reglamento de 1952: a) La facultad de ocupar plazas de categoría inferior a la propia y con carácter de propiedad, siempre que no hubiese vacante en la suya propia, conservando su categoría personal para todos sus efectos, excepto para el cobro de sueldos y toda clase de haberes que serán los correspondientes a la categoría en que presta sus servicios (artículo 160$)$; b) Derecho preferente para cubrir interinidades de cualquier clase que hayan de cubrirse en los Ayuntamientos, figu-

(10) Artículos 41, 48, 49, 50 y 51.

(11) En 1935 se redactó por el Colegio de Secretarios un Anteproyecto de Reglamento, en desarrollo de la Ley municipal de 1935, que en su titulo $L$, capítulo $I$, apartado $E$ ), se ocupó de las situaciones de los funcionarios de Administración local, distinguiendo servicio activo, excedencia y jubilación. 
rando en los escalafones (artículo 162). Sólo cuando quede el concurso desierto, por no acudir a ellos ningún aspirante en expectativa de destino, podrá el Ayuntamiento proveer libremente las plazas.

6. El Reglamento de funcionarios de Administración local DE 1952.

Uno de los aspectos, ha dicho Gallego y Burín (12), que encierran el esencial y permanente valor del Reglamento de 30 de mayo de 1952 es la reorganización de todo el funcionariado local, sentando las bases de una organización definitiva, al evitar, mediante la fórmula de las prescripciones mínimas, igualitarias, la verdadera anarquía que existía en aquella materia de sueldos, plantillas, denominaciones de los cargos, derechos pasivos, licencias, excedencias, etc.

En definitiva, y hasta la promulgación del vigente Reglamento, sólo estaba regulada la excedencia voluntaria, concebida como licencia, con escaso rigor científico, para Secretarios e Interventores, en los escasos términos del artículo 34 del Reglamento de 1924. Y, naturalmente, para aquellos funcionarios cuyas Corporaciones hubiesen dado cumplimiento al mandato legal, que no fueron muchas. El resto, dice el citado autor, se mantuvo al margen de toda situación reglamentaria, en la confusión de las interpretaciones perennes y de las concesiones de equidad y discrecionales, lo que en muchos casos condujo a la negación de todo derecho. Los funcionarios subalternos, los de servicios especiales, la policía municipal y los técnicos, hasta los obreros fijos de plantilla han estado durante más de un cuarto de siglo, a partir de 1924, al socaire de todas las incomprensiones e inseguridades (13).

(12) GaLlego y BURín, Alberto: «Contenido orgánico del nuevo Reglamento de funcionarios», en REvista dE ESTUdios DE LA VIDA LoCAL, 1954, número 74, pág. 203.

(13) Ibidem, pág. 204. 


\section{ANTECEDENTES EN LA LEGISLACIÓN`DE LOS FUNCIONARIOS DEL ESTADO.}

Podemos distinguir las siguientes fases, perfectamente delimitadas:

a) Ley y Regiamento de funcionarios de 1918.

La primera referencia general (14) a la excedencia la encontramos en la Ley de funcionarios de 22 de julio de 1918 (Base 4. ${ }^{a}$ ) y en el Reglamento de 7 de septiembre de 1918 (artículos 41 a 51), que distinguen la forzosa y voluntaria; ésta, sin sueldo, se podía conceder por tiempo no inferior a un año ni superior a diez, no computándose el tiempo a ningún efecto. Hay que advertir que el ámbito de aplicación del Reglamento de 1918 es restringido, pues sólo afecta a los cuadros generales, no a los técnicos o especiales.

\section{b) La Ley de 1954 sobre situaciones administrativas.}

La confusión reinante en la materia por la multiplicidad de disposiciones posteriores para los funcionarios de diversos Ministerios, no siempre concordantes (15), finalizó (16) con una Ley especial sobre situaciones de los funcionarios de la Administración civil del Estado, que lleva fecha de 15 de julio, de «carácter

(14) A la excedencia se refirieron las Leyes de Presupuestos de 29 de junio de 1890 y 30 de junio de 1892, y múltiples disposiciones posteriores.

(15) Lo que dió lugar a que el sistema de la Ley de 1918 resultara incompleto para el fin por ella perseguido, y a que con el procedimiento fragmentado y ocasional de llenar sus lagunas se originaran diversos tratamientos para situaciones realmente idénticas. (Preámbulo de la Ley de 15 de julio de 1954, párrafo $3 .^{\circ}$ )

(16) Deroga la Ley y Reglamento de 1918 en esta materia, y en general según su propio texto, «cuantas disposiciones de carácter general y especial difieran o se opongan a lo que en esta Ley se establece, en cuanto a situación y derechos de los funcionarios en los casos a que la misma se refiere» (Disposición derogatoria). Concediéndose un plazo máximo de seis meses a los Ministerios respectivos para adaptar los Reglamentos orgánicos de todos los Cuerpos que de ellos dependan y normas que los complementen a los preceptos contenidos en esta Ley (Disposición adicional segunda). 
general. (17) y texto único en la materia como avance de una futura revisión total de la Ley de funcionarios civiles» (18).

Distinguió tres clases de excedencia (artículo 6.) : especial (artículo 7.o) (19), forzosa (artículo 8.o) y voluntaria. Esta última comprendía dos casos distintos: 1) Cuando se solicite por pertenecer a otro Cuerpo del Estado o de la Administración local y esté en alguno de estos en cualquiera de las situaciones de servicio activo, supernumerario o excedente especial o forzoso (artículo 9., A). 2) A petición del interesado por «conveniencia o necesidad particular», quedando su concesión subordinada a la «buena marcha del servicio» (artículo 9.o, B). Tiene como duración mínima la de un año (artículo 15, 3.), sin que haga alusión alguna a límite máximo de duración, como hacía el Reglamento de 1918, según vimos. Este segundo caso es la auténtica excedencia voluntaria.

En ambos casos no se perciben derechos económicos, no se reserva la plaza, aunque los excedentes figuren en el escalafón de origen, ni es abonable el tiempo que permanezcan en esta situación (artículo 15).

\section{c) Las Leyes del Movimiento de Reforma administrativa.}

La Ley de Bases de funcionarios civiles del Estado, de 20 de julio de 1963, culminación formal de un proceso de reforma ad-

(17) Deja en vigor, sin embargo, la Ley de 15 de julio de 1952, que establece la situación de excedencia activa para el profesorado oficial de Centros docentes dependientes del Ministerio de Educación Nacional, y el Decreto de 11 de agosto de 1953, que establece la situación de excedencia especial para las Maestras casadas (art. 6..$^{\circ}$, párrafo último). El primer supuesto está hoy recogido en el artículo 46 y el $2 .^{\circ}$, párrafo segundo, lle la Ley articulada, pero no así en el segundo supuesto.

Sobre la prevalencia de la Ley de 1954, con relacion al ordenamiento de 1918, y la generalidad y amplitud de su ámbito de aplicación, puede verse la sentencia del Tribunal Supremo de 3 de octubre de 1959.

(18) Preámbulo de la Ley de 15 de julio de 1954, párrafo último, y artículo $1 .^{\circ}$

(19) Como excedencia especial, con los efectos del artículo $13,1.0^{\circ}$, de la Ley de 15 de julio de 1954, fué considerada la de los funcionarios de la Administración civil del Estado que con autorización del Jefe de su Departamento sean contratados por algún organismo internacional, por los Servicios de Asistencia Técnica de las Naciones Unidas o por algún Gobierno extranjero (artículo 1.9 de la Ley" de 17 de julio de 1958). Hoy este caso está 
ministrativa que arranca, por señalar una fecha, de 1956 (20), hubo de tener en cuenta la Ley de 1954, por su indudable modernidad (21), por lo que la Base $V$ se remite en materia de excedencias, en sus diversas modalidades, al igual que en lo relativo a contenido, causas y efectos de las situaciones administrativas de servicio activo, supernumerario y suspensión, a aquella Ley del año 1954.

La Ley de 7 de febrero de 1964, que articula la de Bases mencionada, se ocupa de la excedencia voluntaria, en términos análogos en lo fundamental a la Ley de 1954 (22), como veremos en su momento, con variaciones de detalle.

\section{FUENTES}

\section{Directas.}

En el Derecho local la excedencia voluntaria está hoy regulada fundamentalmente en el Reglamento de funcionarios de Administración local de 30 de mayo de 1952, dentro de su capítulo IV, sobre situaciones de los funcionarios, y sección $4 .{ }^{a}$, cese en el servicio activo, artículos $56, d$ ), 62 y 63, siendo de aplicación el 72 sobre declaración de las situaciones administrativas. De modo incidental se refieren a la misma los artículos del mismo Reglamento, $39 ; 47,5 . \circ ; 48,2 . \circ ; 50,2 . \circ$, y $55 ; 58,4 . \circ$, y $60,2 . \circ$ Se concibe como derecho en el 78, 5.o, disfrute de excedencias en forma re-" glamentaria.

Rigen también con el carácter de fuente directa las siguientes disposiciones: a) Decreto de 1 de marzo de 1962, núm. 399/62, sobre régimen de los furcionarios femeninos de Administración lo-

recogido entre los de situación de supernumerario por la Ley articulada (artículo $46,1, c)$, que se remite a dicha Ley de 17 de julio de 1958.

(20) Fecha de creación de la Secretaría General Técnica de la Presidencia del Gobierno por Decreto-ley de 20 de diciembre de 1956, como organismo encargado de la reforma de la Administración.

Puede verse García PASCUAL: «Evolución y situación actual del Estatuto de funcionarios en España», en Documentación Administrativa, número 4, 1958, pág. 30.

(21) Preámbulo de la Ley de Bases, II, 3, pág. 87, Edic. Boletín Oficial del Estado, Madrid, 1964.

(22) Artículos $\left.40, b) ; 43,3 ; 45 ; 51,1 .^{\circ}, d\right), 2 .^{\circ}$ y $3 .{ }^{\circ} ;$ y $86,2 .^{\circ}$ 
cal; b) Decreto de 8 de agosto de 1962, núm. 2.151/62, modificando artículos del Reglamento sobre excedencia voluntaria, 62, $2 .^{\circ}$ y $68,3 . .^{\circ}$; y c) Ley de 17 julio de 1958 sobre funcionarios al servicio de organismos internacionales.

\section{SuPletorias.}

La Ley articulada de funcionarios civiles del Estado, aprobada por Decreto 315/1964, de 7 de febrero, es supletoria según su artículo 2, 3., respecto de los de Administración local, y en este carácter serán de aplicación a éstos sus artículos $40, b) ; 43$, $\left.3 . \circ ; 45 ; 51,1 .^{\circ}, d\right), 2 .^{\circ}$ y $3 .^{\circ} ;$ y $86,2 .^{\circ}$

\section{Complementarias.}

Tal carácter tienen todas las disposiciones legales relativas al régimen de Administración de Municipios y Provincias que no siendo incompatibles con la Ley de Régimen local, texto articulado de 1955, la complementen (disposición final primera). Difícil es encontrar preceptos sobre excedencia voluntaria anteriores a 1950, que sean aplicables como complementarios a esta Ley.

Sin embargo, podría señalarse alguno. Tal la facultad de ocupar plazas de inferior jerarquía, regulada por la Ley municipal de 1935, derogada, lo mismo que los Estatutos municipal y provincial, por dicha dispusición final.

\section{POR víA DE ANALOGÍA.}

La Ley de 15 de julio de 1954 sobre situaciones de los funcionarios públicos ha sido derogada en virtud de la disposición final tercera de la Ley articulada, al menos en cuanto a los funcionarios civiles del Estado se refiere, sin perjuicio de los efectos que pueda surtir en relación con otros funcionarios y autoridades (23).

(23) El Decreto número 4.157/64, de 23 de diciembre, deroga o declara la inaplicabilidad a los funcionarios públicos de diversas disposiciones, en cumplimiento de la disposición final 3." de la Ley de Bases de funcionarios civiles del Estado, y número $2 .^{\circ}$ de la disposición final 3.' de la Ley articulada. En su articulo $30^{\circ}$ declara la inaplicabilidad a tales funcionarios, que han de quedar sujetos a los preceptos de la Ley articulada, «sin perjuicio de los efectos que dichas disposiciones puedan surtir en relacion con otros funcionarios 
Con relación a la Administración local, no ha sido ni es de aplicación directa ni supletoria, pero nada se opone a que por vía de analogía y de equidad pudiera tenerse en cuenta para aquellos casos no previstos en las fuentes directas o supletorias anteriormente expuestas.

\section{CONCEPTO Y NATURALEZA}

\section{CONCEPTO DOCTRINAL.}

Es difícil dar una definición de la excedencia debido, por una parte, a su misma generalidad, pues abarca diversas figuras con régimen y efectos muy diversos, $y$, por otra, a la dificultad de deslindarla de la serie de figuras jurídico-administrativas afines, que: constituyen las diversas situaciones en que pueden encontrarse los funcionarios en orden a la prestación de sus servicios a la Aäministración o a la misma relación jurídica de servicio.

$\mathrm{Si}$ atendemos a su origen etimológico y usual, funcionario excedente, de «exceder», es tanto como funcionario sobrante. Trasladado esto al campo del Derecho administrativo, excedente sería el funcionario sobrante en virtud de la reducción o supresión. de plazas de plantilla. Pero este concepto que configura la excedencia como forzosa en todo caso, no abarcaría la modalidad de voluntaria.

Desde el punto de vista de la relación jurídica de servicios, GuAIta la ha definido como «interrupción de la relación jurídica. de servicios no debida a sanción». Concepto que la aisla de la situación de extinción de la relación de servicios (separación, jubilación y retiro, renuncia) y del de interrupción en la prestación de servicios, que no produce interrupción de la relación jurídica. de servicios (permisos, dispensas, vacaciones, licencias) (24).

Pero no parece que la excedencia interrumpa (rompa temporalmente) la relación jurídica de servicio que liga al funcionario

y autoridades», de la Ley de 15 de julio de 1954 sobre situaciones de los funcionarios. También se derogan todas las que hayan sido dictadas para la mejor interpretación o cumplimiento de la misma (artículo 1.9,-párrafo 1.\%).

(24) Guaita, en el artículo «Excedencia», de la Enciclopedia Jurídica. SEIX, Barcelona, 1958, tomo IX, pág. 186. 
con la Administración. A nuestro modo de ver, y más que una interrupción de toda relación, hay una interrupción, cualificada («cese», dice el Reglamento de funcionarios de Administración local) por su especial gravedad, en la prestación de servicios por parte del funcionario, que sigue siéndolo jurídicamente, aunque sin reserva de plaza ni derechos económicos, pero conservando otros derivados de tal condición de funcionario.

$Y$ si quisiéramos distinguir esta situación, que no lleva consigo reserva de plaza ni derechos económicos y que es de mayor duración, de otras en que, por el contrario, se produce aquella reserva, puede haber asimismo ciertos derechos económicos, y son, desde luego, de menor duración, podríamos hablar en el primer caso de cese en el servicio activo, y de interrupción en el servicio en el segundo.

De esta forma, podría definirse la situación de excedencia voluntaria como aquella situación o estado en que puede encontrarse el funcionario en propiedad por su propia voluntad, caracterizada por el cese de sus servicios (sin pérdida de la plaza) y, como contrapartida, de sus derechos económicos, aunque conservando otros (por seguir vigente su relación jurídica de servicio con la Administración), fundamentalmente el de reingreso en determinadas condiciones.

\section{CONCEPTO LEGAL.}

Del articulado del Reglamento de 1952 puede obtenerse la siguiente definición de la excedencia voluntaria: situación administrativa del funcionario que cesa en el servicio activo por voluntad propia expresa o implícita, con privación del cargo que desempeña, pero permaneciendo en el escalafón o Cuerpo respectivo (artículos 62 y 63 en relación con el 55 y 72).

Es decir, cesa la prestación del servicio, y con ello se pierde el cargo (pues no es mera «interrupción» del servicio), pero se continúa ligado a la Administración, permaneciendo en el escalafón con los efectos jurídicos que después regula el mismo Reglamento. 


\section{FUNDAMENTO}

Desconocida por los Derechos extranjeros, la modalidad de excedencia voluntaria tiene una justificación menos fácil que la fcrzosa. El interés publico, que aconseja la supresión de una plaza, es la causa determinante del pase del funcionario a la situación lógica de sobrante o excedente (forzoso), lo que explica que el tiempo le sea abonable y que perciba gran parte de su retribución, aun sin prestar servicio.

Pero el caso de la excedencia voluntaria es otro. Por que el interés contemplado fundamentalmente por la Ley es aquí el del propio funcionario que puede necesitar de un largo período de tiempo para sus asuntos particulares (25). Estas notas de «interés particular», «voluntariedad» y «larga duración» con interrupción de los servicios (cese) son las que explican todos los efectos de esta situación.

La voluntariedad y la razón de interés particular justifican la ausencia de emolumentos de toda clase y de abono de tiempo. La larga duración explica la no reserva de plaza en aras a la protección que demanda el interés público. La permanencia, por otra parte, de la relación jurídica de servicio explica el derecho preferente del funcionario a ocupar la plaza vacante que hubiese o se produzca, y justificó en otro tiempo su limitación en cuanto a la duración máxima.

Partiendo, pues, del interés particular del funcionario, como derecho reconocido por el ordenamiento, se llega a un equilibrio entre el interés del funcionario y el público. Este, en todo caso, quedará atendido cubriéndose la vacante producida, bien en propiedad, bien interinamente, $o$ incluso mediante la interinidad de otro funcionario de la misma plantilla. El funcionario, por razón de su condición (que le supuso unas pruebas o méritos previos al nombramiento), conserva su derecho al reingreso caso de existir

(25) Para períodos más cortos, tratándose de interés particular, están previstas las licencias por motivos de descanso anual (un mes), enfermedad (hasta un año), «asuntos propiosi ordinarios (hasta seis meses) y estudios de perfeccionamiento profesional (hasta un curso académico). 
vacante, pues, supuesta ésta y desear el reingreso, aquél debe ser preferido.

En definitiva, su fundamento no difiere del de las licencias voluntarias. Tan sólo que por su mayor duración comporta, en defensa del interés público, unos efectos más severos para el funcionario: el interés particular de éste precisa un período de tiempo de interrupción de sus servicios tan extenso que la interrupción se transforma en cese en el mismo.

Ninguna consideración de justicia natural podría encontrarse para fundamentar este derecho que nuestro ordenamiento, más generoso que otros, ha concedido a sus funcionarios. Prueba de ello es que no es institución universalmente admitida, sino peculiar de nuestro ordenamiento, que también en el campo del Derecho administrativo se hã mostrado en esta ocasión tan respetuoso de la voluntad particular, como en el campo del Derecho civil en ocasión de muy diversas instituciones.

Ninguna justificación jusnaturalista tiene este derecho, decimos, si no es que siendo favorable al funcionario no perjudica a la Administración, en virtud de las medidas que ésta adopta. Pero ro deja de ser paradójico que quien se ligó con la Administración para la prestación de sus servicios (la nota de permanencia es característica de la definición del funcionario en propiedad) puedà desligarse de la prestación de tales servicios por tiempo ilimitado a su voluntad, pero conservando vigente aquella relación jurídica, que le garantiza su vuelta a dicho servicio con tal que haya plaza vacante.

No obstante, y si ponemos esta cuestión en conexión con la insuficiencia de retribución de la función pública, podríamos encontrar una mayor justificación práctica, que no jurídica, a esta institución. Si el funcionario se ve obligado a tener otros «asuntos propios», debido precisamente a aquella insuficiencia en la retribución, y necesitara un período largo de tiempo para poner en marcha o intensificar aquellos asuntos, o simplemente para probar fortuna en otra profesión, quizá para emigrar temporalmente en busca de unos ingresos rápidos y muy superiores a los que la Administración proporciona, sería justo que esta situación de ex- 
cedencia voluntaria con sus beneficiosos efectos, especialmente en orden a un eventual reingreso, le amparara.

La Administración, por otra parte, también tiene interés en no perder definitivamente al elemento humano, que habiendo demostrado una suficiencia con motivo de su ingreso, incrementada con el ejercicio de unas funciones públicas, es de gran valor por razón de su experiencia, no fácilmente improvisable, para el adecuado desarrollo de tales funciones. $Y$ si bien se considera, no comporta para la Administración más obligación que adjudicar la plaza, caso de vacante, al excedente voluntario con preferencia al extraño que pretende por vez primera el ingreso a su servicio. De hecho, esta institución, por las muy diversas circunstancias que en la vida de toda persona pueden presentarse con exigencia de cese temporal en la prestación de la función pública, ha prestado a los funcionarios innumerables beneficios, sin que lá permanencia y buen funcionamiento de los servicios públicos sufriera por ello detrimento alguno.

La equidad, más bien que un jus strictum, puede en último término servir para justificar la insticución, tan española, de la excedencia voluntaria.

\section{CONCLUSIONES}

1. - La situación jurídica de la excedencia voluntaria, peculiar del Derecho español, tiene como finalidad primordial el interés propio del funcionario, aunque el Derecho administrativo señale lus limitaciones y condiciones necesarias para que no perjudique eí interés que el servicio público representa.

$2 .^{a} \quad$ En su esencia, supone un cese en la prestación de servicios, quedando vigente la relación jurídica de servicios, que liga al funcionario con la Administración, aunque se extinga la otra relación llamada «orgánica» que es la que se tiene «en cuanto titular» (26).

3.- En el Derecho local se concibe al principio esta institu-

(26) García Trevijano: «Relación orgánica y relación de servicios en 10 s funcionarios públicos», en $R$. $A$. $P$., núm. 13, págs. 64 y ss. 
ción muy confusamente y con poca técnica jurídica, como licencia ilimitada, que es causa de mera «interrupción» en la prestación del servicio. Desde el Reglamento de 1952 todo el funcionariado local disfruta de una regulación en la materia bastante elaborada, perfecta, uniforme y cierta, con exclusión de toda arJitrariedad y confusión en sus líneas básicas.

4. En el ámbito de la Administración central, ante la complejidad y confusión reinante en la materia a causa de las múltiples disposiciones aparecidas para complementar la legislación de funcionarios de 1918, se dictó en 1954, dos años más tarde que el Reglamento local, una Ley especial sobre situaciones, juzgada como necesaria, pero inoportuna al formularse aisladamente, sin constituir parte de un ordenamiento de los funcionarios a que se refiere (27). Hoy, al encuadrarse tal contenido casi sin variación en la Ley articulada, por cierto de aplicación supletoria respecto a los funcionarios locales, se ha restablecido en este aspecto la unidad del ordenamiento juridico de la función pública central y facilitado el acercamiento entre ambos Derechos funcionariales.

5. - En suma, la institución de excedencia voluntaria, si no de gran trascendencia desde el punto de vista de la teoría del Derecho administrativo (28), es de uso muy frecuente en conexión con el problema de la insuficiencia de la retribución de la función pública, planteando numerosos problemas prácticos que ha ido abordando la Jurisprudencia (29). Y responde a aspectos muy humanos del funcionario, que aquél debe tener en cuenta, pues aparte de este aspecto de equidad, supone gran ventaja para la misma Administración sin quebranto alguno para el servicio, en cuanto supone medio adecuado de recuperación de elementos. personales ya formados y experimentados en su servicio.

(27) Serrano Guirado: «La Ley de 15 de julio de 1954, sobre situaciones de los funcionarios de la Administración civil del Estado», en $R$. A. P., número 15, págs. 240 y ss.

(28) GuaIta: Obra citada.

(29) Puede verse, en cuanto a los peculiares problemas que el tema plantea, Clavero AREvalo: «Las situaciones de los funcionarios en los casos de alteración de términos municipales», en Estudios en homenaje a Gascón "u Marín. Madrid, 1952, págs. 3-28. 